Introduction We propose to perform near full-length deep sequencing of HIV-1 genomes from approximately 100 newlydiagnosed cases in San Francisco in the previous year (2016), using stored specimens from the clinical genotyping service that serves the majority of HIV cases in San Francisco.

Methods Stored, frozen blood plasma from approximately100 newly-diagnosed cases in San Francisco over the previous year will be analysed. Four amplification products covering most of the HIV-1 genome will be derived by RT-PCR adapted from existing protocols. These protocols have been shown to be successful for the near full length analysis of approximately $85 \%$ of specimens having viral load greater than 10000 copies per $\mathrm{ml}$, which represent the majority of newly diagnosed people in San Francisco. Briefly, four overlapping regions spanning all reading frames of the HIV genome will be amplified in a published one-step RT-PCR strategy. Pooled amplicons will be purified and sequenced on an Illumina HiSeq instrument operated by GENEWIZ.

Results This work is ongoing and we have generated approximately half of the near full length HIV genomes for this project. This data and techniques will be presented as part of the results.

Conclusion Deep sequencing provides better resolution for characterising the duration of infection. Viral diversity increases over time on average and can be estimated from the frequency of sequence ambiguities in population sequences. However, sequence ambiguities can occur due to dual infection, which can occur early in infection, and make the virus population sequence appear older.

Support This project is funded entirely by an RO1 grant from the National Institutes of Health, USA

\section{Epidemiology, Monitoring and Evaluation}

\section{P3.01 TRENDS IN HIV AND HTLV INFECTIONS ACCORDING TO AGE AND RISK FACTORS IN BRAZIL}

Adele Caterino-De-Araujo, Karoline Rodrigues Campos.

$10.1136 /$ sextrans-2017-053264.238

Centro de Imunologia, Instituto Adolfo Lutz, São Paulo, SP, Brazil

Introduction From 1980 to June 2016 the Ministry of Health of Brazil notified 842,710 HIV/AIDS cases; 136945 new cases were notified after 2007 (71,396 in the Southeast region). An increase in the number of individuals aged 15 to 34 years was observed, with a male to female ratio of $2.4: 1$ and sexual exposure as the major risk factor. At present, 50\% of males referred homosexual practice and 9\% bisexual; conversely, $96 \%$ of females are heterosexual. HTLV-1 and HTLV2 are endemic in Brazil; estimated in 2.5 million people. Since HIV and HTLV share routes of virus transmission, coinfection of such virus could occur.

Methods The present study discloses the age and gender of 1,715 HIV-infected individuals of AIDS care services (São Paulo, Brazil) in period from 2010 to 2016, whose blood samples were sent to Instituto Adolfo Lutz for HTLV infection analysis, and they were divided according to sex in five agegroups $(\mathrm{G} 1=16-25$ years, $\mathrm{G} 2=26-30$ years, $\mathrm{G} 3=31-40$ years, $\mathrm{G} 4=41-50$ years, and G5 $=>50$ years). HIV/HTLV positive cases were analysed in each group.
Results The increase of the HIV-infected male of G1 was detected ( $<10 \%$ in 2010 vs. $33 \%$ in 2016) as well in patients of G2 (<10\% in 2010 vs. $22 \%$ in 2016). Among females, although in minor percentages, an increase in HIV infection in patients of 16 to 25 years was detected. Concerning HIV/ HTLV coinfection, during the years from 2010 to 2014 all cases were detected in patients over 30 years old, but from 2015 to 2016 three cases of HTLV infection were detected in patients with less than 30 years of age.

Conclusion The increase in the last years in Brazil in the number of HIV infections in the second and third decades of life is of concern, and could be related to unprotected sexual contact and promiscuity after consuming drugs (alcohol, marijuana and others). Although HTLV was more efficiently transmitted by parenteral route, sexual transmission seems to account for the new HTLV infected individuals in Brazil. Surveillance of such viruses is important to properly control these viruses spread.

Support: CNPq PD\#302661/2015-8

\section{P3.02 MOTHER-TO-CHILD TRANSMISSION OF HIV ELIMINATION CERTIFICATION PROCESS IN BRAZIL}

AS Benzaken, JP Toledo, RG Corrêa, GF M Pereira, AR P Pascom, AR C Cunha, RA Coelho, RA Ribeiro. Department of STI, HIVIAIDS and Viral Hepatitis, Ministry of Health of Brazil

\subsection{6/sextrans-2017-053264.239}

Introduction MTCT is the main HIV infection route in Brazilian children. The rates of AIDS detection in children under five years have been decreasing in Brazil since 2004, from $5.6 / 100,000$ inhabitants in 2003 to $2.5 / 100,000$ inhabitants in 2015, with southeast area decreasing fastly and brought the national rate down. To contribute to the reduction in MTC transmission of HIV in Brazil, the Ministry of Health $(\mathrm{MoH})$ launched at the end of 2016 the certification process of cities that eliminated MTCT. The objective of this work is to present the Brazilian process of implementation of HIV MTCT elimination certification.

Methods Experts working group was establish to adapt PAHO criteria to the Brazilian scenario. We included as impact indicators the HIV detection rates among children by birth year; and the proportion of children until 18 months old that were exposed to HIV and was infected, and, in addition must have more than 100000 inhabitants. We analysed data from our national surveillance systems, between 2012 and 2014, to select the municipalities to initiate the process of certification. Results To be eligible municipalities has to present HIV detection rates $\leq 0.3 / 1000$ live births and/or proportion of children exposed to HIV classified as infected $<2 \%$. 3816 out of 5,570 Brazilian municipalities were eligible for certification. Among them 1949 presented the minimum epidemiological criteria to start the certification process, but just 82 metropolises with more than 100000 inhabitants were eligible to start the process.

Conclusion The selected cities must create a multidisciplinary working group to investigate the impact and process indicators established, and need to meet some process indicators that includes prenatal coverage; HIV tests performed during prenatal among pregnant women; and antiretroviral therapy among infected pregnant. Based on these evidences the cities will receive a certificate of elimination of MTCT HIV. The 
certification processes is a way to further encourage other municipalities to eliminate MTCT in their territory.

\section{P3.03 PREVALENCE OF HIV/SYPHILIS AND QUALITY OF ANTENATAL CARE FOR PREVENTION OF MOTHER-TO- CHILD TRANSMISSION (PMTCT) IN PARTURIENT AND PUERPERAL WOMEN IN PARAGUAY}

Aguilar Gloria ${ }^{1,2}{ }^{1}{ }^{1}$ Kawabata Anibal, ${ }^{3}$ Miranda AE, 'Estigarribia Gladys. 'Samudio Tania. ${ }^{1}$ Recalde Hugo, 'Giménez Liliana, 'López GladdysRios-González Carlos Miguel, '. ${ }^{1}$ Universidad Nacional de Caaguazú, Coronel Oviedo, Paraguay; ${ }^{2}$ Universidade Federal do Espirito Santo (UFES), Vitoria, Brazil; ${ }^{3}$ National Program of HIVIAIDS,Asunción, Paraguay

\subsection{6/sextrans-2017-053264.240}

Introduction In recent years Syphilis has been a priority public health problem in Latin American and Caribbean countries (LAC), added to the problem of mother-to-child transmission (MTCT) of HIV. Our goal is to determine the prevalence of $\mathrm{HIV} /$ syphilis and measure the quality of antenatal care for prevention of MTCT in parturient and postpartum women attending public health facilities in Paraguay in 2013.

Methods Descriptive cross-sectional study using a standard survey and linked confidential serological tests. Data included public units at National level. A stratified two-stage cluster sampling was performed and data were expressed in measures of central tendency, dispersion and tables of proportions.

Results A total of 8.256 postpartum and parturient women were admitted to the study and $92.48 \%$ attending prenatal care. HIV prevalence in postpartum/parturient women was $0.50 \%$ (95\% CI $0.36-0.69$ ) and of Syphilis was $4.18 \%$ (CI $95 \% 3.75$ to 4.65 ). In $65.93 \%$ of them, the first prenatal visit was performed before 20 weeks of gestation. $72.04 \%$ performed 4 or more prenatal visits and $58.03 \%$ of pregnant women presented both, prenatal visit before 20 weeks and $\geq 4$ prenatal visits. In $85.59 \%$ and $83 \%$, the tests for HIV and syphilis diagnosis were performed during pregnancy. The diagnostic tests fo sexual partners were available in $12.50 \%$ and $24.40 \%$ for HIV and syphilis, respectively. The treatment of sexual partners of pregnant women with syphilis was $21.40 \%$.

Conclusion HIV prevalence was low; however the prevalence of syphilis was high in postpartum and in parturient women in Paraguay. The percentage of prenatal care before 20 weeks of gestation was low and the percentages of performing the tests on the sexual partners and the treatment of syphilis were very low. Improving the access to and quality of antenatal care services and implement effective strategies for the notification and treatment of sexual partners in health services the timely implementation of 1 st prenatal care and, in particular, to include strategies for testing sexual partners.

\section{P3.04 PREDICTORS OF MORTALITY IN CHILDREN UNDER 15 YEARS OLD WHO ACQUIRED HIV FROM MOTHER TO CHILD TRANSMISSION IN PARAGUAY}

\footnotetext{
${ }^{1,2,3} \mathrm{G}$ Aguilar, AE Miranda ${ }^{2},{ }^{3} \mathrm{~T}$ Samudio, ${ }^{1} \mathrm{~A}$ Kawabata, ${ }^{4} \mathrm{~S}$ Muñoz ${ }^{5} \mathrm{~F}$ Galeano. ${ }^{1}$ Universidad Nacional de Caaguazu, Coronel Oviedo, Paraguay; ${ }^{2}$ Universidade Federal do Espirito Santo (UFES), Vitoria, Brazil; ${ }^{3}$ National Program of HIV/AIDS,Asunción, Paraguay; ${ }^{4}$ Universidad de la Frontera-Facultad de Medicina, Paraguay; ${ }^{5}$ Temuco, Chile Instituto de Medicina Tropical, Asunción, Paraguay
}

Introduction Paraguay has made efforts to improve the response to HIV infection, and it is important to assess the impact of interventions in paediatrics. To estimate predictors of mortality in children who acquired HIV from mother to child transmission, between January 2000 and December 2014.

Methods A birth cohort study among persons living with HIV infection (PLWH), they were $<15$ years of age at enrollment. We abstracted data from clinic records, using a standardised form; obtained the data of death from clinic records and confirmations of deaths from deaths' certificates. We used survival analysis techniques to estimate the incidence of death.

Results A total of 302 subjects were included in the survey. $71.4 \%$ younger than six years of age, $51.0 \%$ female, $74.3 \%$ were from the metropolitan area. There were 52 deaths (17.2\% of participants), resulting in an overall mortality rate of 1.86 deaths $/ 100$ person-years [ $95 \%$ confidence interval (CI) 1.39, 2.44]. The Children with baseline HIV viral load >100000 copies/mL were four times more likely to die than children with baseline HIV viral load $\leq 100.000$ (HR, 4.47; 95\% CI: 1.79, 11.10). Regarding age-stratified staging of disease, those children with stage 3 were four times more likely to die compared with children on Stage (1 and 2) (HR: 4,19; 95\% CI: 1,50,11,70). Those children with haemoglobin level $\leq 9 \mathrm{~g} / \mathrm{dL}$ at baseline have four time more chance to die compared with haemoglobin level $\geq 9 \mathrm{~g} / \mathrm{dL}$ (HR: 3.90; 95\% CI1.61, 9.80).

Conclusion The mortality of children with HIV in Paraguay is low. High HIV viral load, late stage and moderate or severe anaemia at first diagnosis time are associated with mortality. Improving prenatal care and paediatric follow-up in an effort to diagnose vertically infected children as early as possible should be an integrated part of the healthcare provided to the child with AIDS, and it is very important an action that may increase survival in these children.

Support: University of California, San Francisco's International Traineeships in AIDS Prevention Studies (ITAPS), U.S. NIMH, R25MH064712

\section{P3.05 CONTRIBUTION TO THE PARENTS' KNOWLEDGE OF ABOUT HERPES INFECTIONS IN CHILDREN}

${ }^{1}$ AJ Giesteira, ${ }^{2}$ DC Ferreira, ${ }^{3} \mathrm{HLB}$ Reis, ${ }^{4}$ MRL Passos. ${ }^{1}$ Mestranda em Materno Infantil UFF, Brazil; ${ }^{2}$ Professor da UNESA e UVA, Brazil; ${ }^{3}$ Doutoranda - UFES, Brazil; ${ }^{4}$ Professor Titular e chefe do setor de DST - UFF, Brazil

\subsection{6/sextrans-2017-053264.242}

Introduction The Herpes Simplex Virus (HSV) is an infection caused by two types of viruses. The type-1 (HSV-1), which is more common in the oralabial region and the type 2 (HSV-2) in the genital region. The estimate is that $60 \%-80 \%$ of adults in the world have the type 1 virus, and the type- 2 prevalence is lower. $90 \%$ of individuals affected by the virus are asymptomatic.

Methods This is a sectional and quantitative study, where a public interview was used with those responsible for children, who were infected or not by herpes simplex. The total of 140 guardians were evaluated, being 121 women and 19 men, and through these data regarding their children was collected. The clinic scenario was women specialised care. The tests used in the statistics analysis were: chi-square and Fisher Exact test. 